\title{
Mitochondrial genomes and comparative analyses of Culex camposi, Culex coronator, Culex usquatus and Culex usquatissimus (Diptera:Culicidae), members of the coronator group
}

Bruna Demari-Silva ${ }^{1 *}$, Peter G. Foster ${ }^{2}$, Tatiane M. P. de Oliveira ${ }^{1}$, Eduardo S. Bergo ${ }^{3}$, Sabri S. Sanabani ${ }^{4}$, Rodrigo Pessôa ${ }^{4}$ and Maria Anice M. Sallum ${ }^{1}$

\begin{abstract}
Background: The Coronator Group currently encompasses six morphologically similar species (Culex camposi Dyar, Culex coronator Dyar and Knab, Culex covagarciai Forattini, Culex usquatus Dyar, Culex usquatissimus Dyar, and Culex ousqua Dyar). Culex coronator has been incriminated as a potential vector of West Nile Virus (WNV), Saint Louis Encephalitis Virus (SLEV), and Venezuelan Equine Encephalitis Virus (VEEV). The complete mitochondrial genome of Cx. coronator, CX. usquatus, Cx.usquatissimus, and Cx. camposi was sequenced, annotated, and analyzed to provide genetic information about these species.

Results: The mitochondrial genomes of $C$. coronator, $C$. usquatus, Cx.usquatissimus, and $C$ x. camposi varied from 15,573 base pairs in $C x$. usquatus to 15,576 in Cx. coronator. They contained 37 genes (13 protein-encoding genes, 2 rRNA genes, and 22 tRNA genes) and the AT-rich control region. Comparative analyses of the 37 genes demonstrated the mitochondrial genomes to be composed of variable and conserved genes. Despite the small size, the ATP8, ATP6 plus NADH5 protein-encoding genes were polymorphic, whereas tRNAs and rRNAs were conserved. The control region contained some poly-T stretch. The Bayesian phylogenetic tree corroborated that both the Coronator Group and the Culex pipens complex are monophyletic taxa.

Conclusions: The mitochondrial genomes of $C x$. coronator, $C$. usquatus, $C x$. usquatissimus and $C x$. camposi share the same gene composition and arrangement features that match to those reported for most Culicidae species. They are composed of the same 37 genes and the AT-rich control region, which contains poly-T stretches that may be involved in the functional role of the mitochondrial genome. Taken together, results of the $\mathrm{dN} / \mathrm{dS}$ ratios, the sliding window analyses and the Bayesian phylogenetic analyses suggest that ATP6, ATP8 and NADH5 are promising genes to be employed in phylogenetic studies involving species of the Coronator Group, and probably other species groups of the subgenus Culex. Bayesian topology corroborated the morphological hypothesis of the Coronator Group as monophyletic lineage within the subgenus Culex.
\end{abstract}

Keywords: Culex, Coronator Group, Mitochondrial genome, Arboviruses, Vectors

\footnotetext{
* Correspondence: bruna-demary@usp.br

'Departamento de Epidemiologia, Faculdade de Saúde Pública, Universidade de São Paulo, São Paulo, Brazil

Full list of author information is available at the end of the article
}

() Biomed Central

(c) 2015 Demari-Silva et al. Open Access This article is distributed under the terms of the Creative Commons Attribution 4.0 International License (http://creativecommons.org/licenses/by/4.0/), which permits unrestricted use, distribution, and reproduction in any medium, provided you give appropriate credit to the original author(s) and the source, provide a link to the Creative Commons license, and indicate if changes were made. The Creative Commons Public Domain Dedication waiver (http://creativecommons.org/publicdomain/zero/1.0/) applies to the data made available in this article, unless otherwise stated. 


\section{Background}

Culex camposi Dyar, Culex coronator Dyar and Knab, Culex covagarciai Forattini, Culex ousqua Dyar, Culex usquatus Dyar and Culex usquatissimus Dyar are members of the Coronator Group of the subgenus Culex [1]. Morphological features of the fourth-instar larva, pupa and female cannot distinguish among species of the Coronator Group. However, traits of the male genitalia allow species identification. Species of the Coronator Group are largely distributed and some are sympatric in the Neotropics [2]. In southeastern Brazil, for instance, the geographical distribution of $C x$. usquatus, $C x$. coronator and $C x$. camposi overlaps [1]. Phylogenetic relationships among the species remain unresolved, because results of studies employing DNA sequences of the cytochrome c oxidase subunit 1 (COX1) mitochondrial gene $[3,4]$ and of the internal transcribed spacer 2 (ITS2) of the ribosomal DNA [5] showed poorly supported clades. Likely because of the lack of studies, there is no evidence of hybridization among species of the Coronator Group.

Culex coronator is a potential vector of arboviruses. As such, this species may participate in the dynamics of the transmission of the Saint Louis Encephalitis Virus (VESL), the Venezuelan Equine Encephalitis Virus (VEEV), the Mucambo Virus (MV) [6, 7], and the West Nile Virus (WNV) [8]. Experiments of susceptibility of $C x$. coronator to the WNV showed that the population from Florida, USA, is competent in disseminating the WN-FL03p2-3 strain under some conditions; however, the transmission rate decreases at lower temperatures $\left(0-17 \%\right.$ at $25{ }^{\circ} \mathrm{C}$ and $28-67 \%$ at $28^{\circ} \mathrm{C}$ ) [8]. The impossibility of accurately identifying a species can lead to inconclusive studies regarding the vector status of it. The problematic identification of species of the Coronator Group may be causing difficulties in defining the medical importance of this group.

The mitochondrial genome of the majority of the metazoan organisms is a small genome (ranging from 15 to $20 \mathrm{~kb})$. It contains 37 genes, which encode 13 ProteinCoding Genes (PCGs) involved in oxidative phosphorylation, 2rRNA ( $r r n L$ and $r r n S$ ) and 22 tRNAs genes, which are necessary for the translation of the proteins encoded by the genes $[9,10]$. The mitochondrial genome also encompasses a region that is rich in adenine (A) and thymine (T). This AT-rich region starts and controls the replication of the mitochondrial genome [11]. Because of the lack of recombination and fast evolutionary processes in comparison to those that involve nuclear genes, the mitochondrial genome seems to be a source of information that can be employed to address evolutionary processes of both vertebrates and invertebrates [12-14].

Although being largely employed in molecular taxonomy and phylogeny, only Culex quinquefasciatus Say and Culex pipiens L. possess their mitochondrial genome available in the Genbank. Considering the potential taxonomic and phylogenetic content of genes of the mitochondrial genome for Culex species and the role of $C x$. coronator as vector of arboviruses, four species of the Coronator Group were the focus of this study. Next generation sequencing technology was applied to sequence the mitochondrial genomes of Culex coronator, Culex usquatus, Culex camposi, and Culex usquatissimus. The objectives of the study were to: 1) describe the mitochondrial genome of four species of the Coronator Group; 2) to analyze the mitochondrial genome of four species of the Coronator Group; 3) to compare the genomes of species of the Coronator Group with other species of the Culicidae family available in the Genbank; 4) to assess the monophyly of the Coronator Group.

\section{Methods}

\section{Mosquito sampling and DNA extraction}

Mosquitoes and collection data from individuals employed in the study are in Table 1 and Fig. 1. Immature stages were field collected as either larvae or pupae and kept in the laboratory to obtain adults associated with larval and pupal exuviae for species identification. Only males were employed to sequence the mitochondrial genome because species identification is based on traits of the male genitalia (Table 1). Fourth-instar larval, pupal exuviae and dissected male genitalia were mounted on microscope slides in Canada balsam and are deposited in Coleção Entomológica de Referência, Faculdade de Saúde Pública, Universidade de São Paulo, Brazil, as vouchers. Males were kept in $95 \%$ ethanol and stored at $-80{ }^{\circ} \mathrm{C}$ until DNA extraction.

\section{PCR amplification and sequencing}

Genomic DNA was extracted from each mosquito individually using QIAgen Dneasy ${ }^{\odot}$ Blood and Tissue kit (QIAgen Ltd., Crawley, UK) following the same

Table 1 Species, specimen codes, gender, states and geographical coordinates of the collection of localities in Brazil

\begin{tabular}{|c|c|c|c|c|}
\hline Species & Specimencode & Sex & State & Geographicalcoordinates \\
\hline Culex coronator & RS10_109 & $\delta$ & Rio Grande do Sul & $29^{\circ} 39^{\prime} 35^{\prime \prime} \mathrm{S} 50^{\circ} 13^{\prime} 03^{\prime \prime} \mathrm{W}$ \\
\hline Culex usquatissimusAC & AC16_101 & $\hat{\jmath}$ & Acre & $9^{\circ} 41^{\prime} 03^{\prime \prime} \mathrm{S} 67^{\circ} 08^{\prime} 05,3^{\prime \prime} \mathrm{W}$ \\
\hline Culex usquatissimusRO & RO25_19 & $\hat{\jmath}$ & Rôndonia & $10^{\circ} 18^{\prime \prime} 03^{\prime \prime} \mathrm{S} 63^{\circ} 14^{\prime} 09,1^{\prime \prime} \mathrm{W}$ \\
\hline Culex usquatus & SP29_156 & $\hat{\sigma}$ & São Paulo & $21^{\circ} 37^{\prime} 07^{\prime \prime} \mathrm{S} 50^{\circ} 56^{\prime} 24^{\prime \prime} \mathrm{W}$ \\
\hline Culex camposi & MS04_38 & $\delta$ & Mato Grosso do Sul & $19^{\circ} 29^{\prime} 59,4^{\prime \prime} \mathrm{S} 55^{\circ} 36^{\prime} 33,8^{\prime \prime} \mathrm{W}$ \\
\hline
\end{tabular}




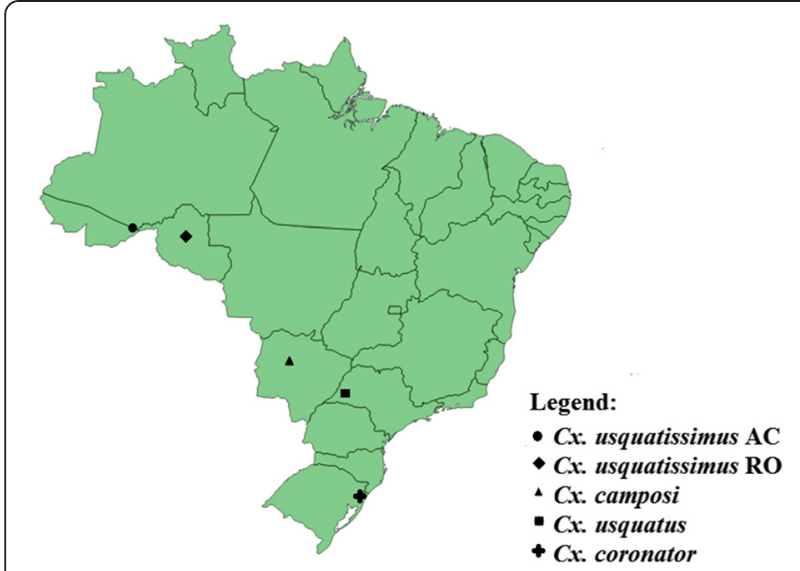

Fig. 1 Map of Brazil showing the collection sites of species of the Coronator Group of Culex (Culex) (Diptera: Culicidae)

procedures adopted by Foster et al. [15]. The mitochondrial genome of each individual was amplified in two PCRs. A long PCR amplification generated a fragment of $\sim 12,000$ base pairs (bp) and a second reaction targeted a fragment of $\sim 4,500 \mathrm{bp}$. Two sets of primers were used as follows: 16Sa (5' CGCCTGTTTATCAA AAACAT 3') and LCO1490 (5' GGTCAACAAATCAT AAAGATATTGG $3^{\prime}$ ) to amplify 12,000 -bp fragment, and 16Sb (5' CCGGTTGAACTCAGATCA 3') and HCO2198 (5' TAAACTTCAGGGTGACCAAAAAAT CA $3^{\prime}$ ) to generate fragments of $\sim 4,500$-bp. See Folmer et al. 1994 [16] for additional information about the LCO1490 and HCO 2198 primers, and Kambhampati and Smith (1995) [17] for $16 \mathrm{Sa}$ and $16 \mathrm{Sb}$ primers. Each PCR reaction was performed using $\mathrm{GoTaq}^{\circ}$ Long PCR Master Mix (Promega, Wisconsin, USA) following the protocols proposed by the manufacturer. The long PCR products were purified in DNA Clean \& Concentrator $^{\text {rm }}$ (Zymo Research, California, USA) and quantified with Qubit (LifeTechnologies, Oregon, USA) for library preparation. Individually barcoded PCR libraries were created for the 12,000 bp and 4,500 bp PCR products employing Nextera ${ }^{\circledR}$ XT DNA Sample Preparation Kit (Illumina, Illinois, USA) and sequenced on the Illumina MiSeq platform with paired-end 250 base pairs chemistry.

\section{Genome assembly and annotation}

Mira v4 software was used for sequence assembly and Tablet to view the assembly $[18,19]$. The MITOS website [20] was used to delimit the genes. Annotation of protein coding genes was conducted using the Wise2 v2.2 package and the HMMER2 models [21] (HMMER v3.1b2; http://hmmer.janelia.org/).

\section{Sequence analysis}

Nucleotide composition values were calculated using the MEGA 6.06 software [22]. The GC-and AT-skews were used to determine strand asymmetry [23]. To measure these values, the following formulas were used: GC-skew $(\mathrm{G}-\mathrm{C}) /(\mathrm{G}+\mathrm{C})$ and AT-skew $(\mathrm{A}-\mathrm{T}) /(\mathrm{A}+\mathrm{T})$. The secondary structure of tRNAs was inferred in tRNAscan-SE 1.21 [24]. A sliding window of $200 \mathrm{bp}$ and steps of $25 \mathrm{bp}$ was implemented to estimate nucleotide divergence. The analysis was performed using the five complete mitochondrial genome sequences in DnaSP v. 5.10.01 [25]. Ratios between non-synonymous $(\mathrm{dN})$ and synonymous (dS) substitution among protein-coding sequences of all pairs of species were calculated in KaKs calculator [26] using a modified Yang-Nielsen algorithm. This ratio is currently employed to estimate if genes are under negative (purifying) selection $(\mathrm{dN} / \mathrm{dS}<1)$, positive (adaptative) selection $(\mathrm{dN} / \mathrm{dS}>1)$, or neutral evolution.

\section{Phylogenetic analysis}

Phylogenetic analysis was carried out using Bayesian inference from the concatenated sequences of all protein coding genes of the five newly sequenced Culex specimens, plus the mitochondrial genomes of four species available in the GenBank, as follows: Cx. quinquefasciatus [HQ724617], Cx. pipiens [HQ724616, HQ724615], Aedes albopicutus [NC_006817] and Anopheles darlingi [NC_014275]. The latter two species were employed as outgroups. Multiple alignments were generated in Clustal X [27] and then edited visually in BioEdit [28] to ensure that genes were in the frame. The best-fit model of nucleotide substitution for each gene was estimated in JModeltest 0.1.1 package [29], under Akaike Information Criterion (AIC). Bayesian analysis was performed in MrBayes v. 3.1.2 [30] and the dataset was partitioned by genes. Two independent runs with one cold and three heated chains each, were implemented for 1,000,000 generations with trees sampled every 100 generations; the consensus topology was generated after a burnin of $25 \%$ of the retained trees.

\section{Results and discussion}

\section{Mitochondrial genome organization and nucleotide} composition

The mitochondrial genomes of $C x$. coronator, $C x$. usquatus, $C x$. usquatissimus and $C x$. camposi contain 37 genes, which have been found in other metazoan and Culicidae species, including 13 protein-encoding genes, 22 tRNAs and 2 rRNA genes , $(r r n L$ and $r r n S)$ and the AT-rich control region [31-34]. The genomes are approximately of the same length of Culex quinquefasciatus (15,587 base pairs): $15,573 \mathrm{bp}$ in $C x$. usquatus and $C x$. usquatissimus from Acre state (Cx. usquatissimus AC); 15,574 bp in $C x$. usquatissimus from Rondônia state ( $C x$. usquatissimus $\mathrm{RO}$ ); and 15,576 bp in Cx. coronator (Table 2). No difference was observed in the length of the 13 protein coding genes. Furthermore, differences in gene length were 
Table 2 Structural feature of the mitochondrial genome of four species of Cx. coronator, Cx. usquatus, CX. camposi, and CX. usquatissimus

\begin{tabular}{|c|c|c|c|c|c|}
\hline Species & Mitoch & tructure in ba & & & \\
\hline & PCG & tRNA genes & rRNA genes & Control region & Total \\
\hline Cx. coronator & 11,226 & 1,482 & 2,124 & 725 & 15,576 \\
\hline Cx. usquatissimus $A C$ & 11,226 & 1,482 & 2,124 & 721 & 15,573 \\
\hline Cx. usquatissimus RO & 11,226 & 1,483 & 2,124 & 722 & 15,574 \\
\hline CX. usquatus & 11,226 & 1,483 & 2,124 & 719 & 15,573 \\
\hline CX. camposi & 11,226 & 1,482 & 2,124 & 719 & 15,570 \\
\hline
\end{tabular}

primarily caused by insertion/deletions in the intergenic spacers and in the AT-control region.

In all species, nucleotide composition was biased toward overall AT content. This AT-bias has been reported in the mitochondrial genomes of other metazoan species [34-37]. In $C x$. coronator, $C x$. usquatissimus AC from Acre state and $C x$. usquatissimus $\mathrm{RO}$ from Rondônia state, the AT content value was $78.6 \%$, whereas in $C x$. usquatus and $C x$. camposi it was $78.9 \%$ (Table 3). These values were similar to those found in other Culicidae species with the mitochondrial genome reported [31-34]. Considering species of the Anopheles albitaris complex, the AT content ranged from $77.1 \%$ to $77.4 \%$; whereas in Cx. quinquefasciatus it was $77.7 \%$, and in Ae. aegypti, $79 \%$. Similar to Anopheles species [34] and other orders of Insecta [36], the value of the AT content increased in the third codon position of the PCGs varying from $81.4 \%$ to $86.6 \%$, being slightly lower than in the control region (89.2 \% to $90.1 \%)$. One explanation for this phenomenon is the "transcription hypothesis of the codon usage" [38]. According to Sun et al. [38], the high availability of ATPs, along with the lack of other NTPs in cells, leads to the maximization of the use of adenines in the third codon position in order to increase the efficacy of the transcription. The overall AT-skew was positive in all species $(0.0025$ for $C x$. usquatissimus $\mathrm{RO}$ and Cx. usquatissimus AC; 0.0012, 0.003 and 0.0038, in $C x$ coronator, $C x$. camposi and $C x$. usquatus, respectively), whereas the GC-skew was -0.15 for all species, showing that adenine and cytosine are in the highest proportion compared to thymine and guanine, respectively, in the majority strand. Those findings are in agreement with other studies of species of the genera Anopheles and Drosophila [34].

\section{The protein-coding genes (PCGs)}

Except for the COX1 gene in which no canonical ATN was found, the majority of the PCGs of Culex species possessed the start codon ATN (Additional file 1). The absence of the ATN start codon in the COX1 gene was found in Cx. quinquefasciatus, Cx. pipiens, Ae. aegytpti and in other insects [31-35] and therefore it has been widely discussed [39]. In 1983, de Brujin [40] proposed a tetranucleotide (ATAA) positioned upstream in the proximity of the opening codon of COX1 (TCG) as a start codon for Drosophila melanogaster. The author hypothesized that if an ATA, a recognized start codon, overlaps a stop codon TAA in the frame -1, the ATA of the tetranucleotide ATAA could function as a highly conserved 0 frame and as an opening frame. Notwithstanding, in the mitochondrial genome of Culex species, the closest ATAA tetranucleotide is located within the trnL2 gene, overlapping 36 base pairs of the gene. Consequently, it is plausible to suppose that the hexanucleotide ATTTAA, which usually flanks the beginning of the COX1 in mosquitoes, is involved in the initiation of the translation signal of this gene, as it was proposed for Tetrodontophora bielanensis [39].

Eleven genes (ATP6, ATP8, COX3, CytB, NAD2, NAD3, NAD4, NAD4L, NAD5, NAD6) have complete TAA stop codons, except for $C O X 1$ and $C O X 2$ genes, which terminate with an incomplete codon $\mathrm{T}$. This phenomenon has been extensively reported in other mitochondrial genomes, especially in $C O X$ genes, and so

Table 3 Overall nucleotide composition and A + T content per structural feature, and by codon position in protein-coding genes

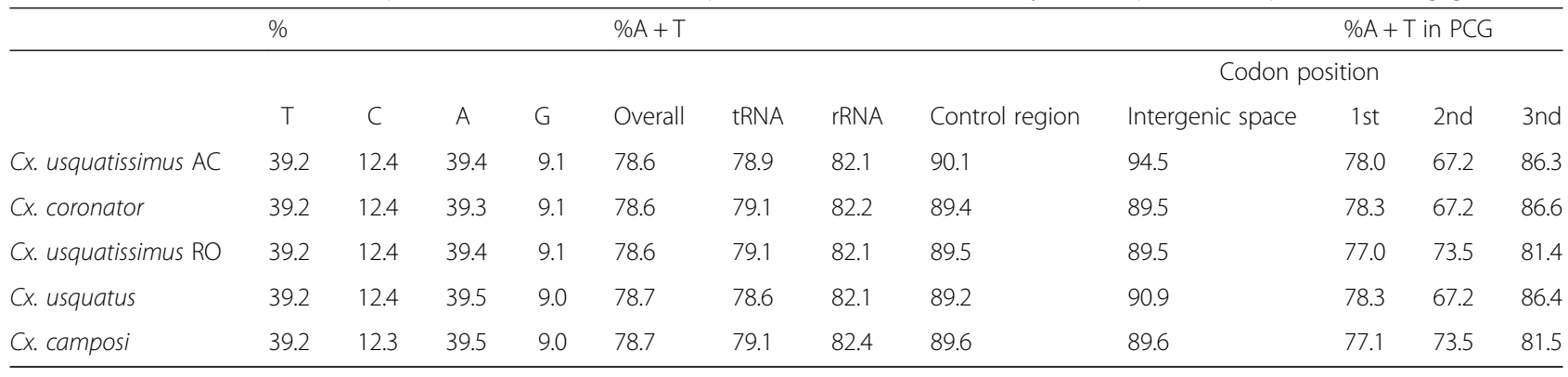


far it has been related to posttranscriptional polyadenylation, during which residual adenines are added in order to originate TAA terminators [34, 36, 41].

A total of 322 nucleotide sites were variable across PCGs of all Culex species analyzed, in which 270 were at the 3rd, 51 at the 1 st and 1 at the 2nd codon position, encompassing most of those transition mutations. As expected, genes with a larger length (NAD2, COX1, NAD4, $N A D 5, C y t B$ and NAD1) concentrated the majority of the polymorphisms; however $C O X 1$,only presented synonymous substitutions, whereas NAD2, NAD5, NAD4, CytB, and NAD1 showed 3,2,1,3, and 2 non-synonymous substitutions, respectively. Additionally, despite the small length, ATP6 and ATP8 were polymorphic genes in Culex species, with 23 (2 non-synonymous) and 4 variable (2 non-synonymous) sites. Additionally, the $\mathrm{dN} / \mathrm{dS}$ ratios (Fig. 2) were very low, ranging from 0.0 to 0.09 , suggesting that all PCGs are under strong negative selection. Despite that, the strength of selection varies among genes; COX1, COX2, COX3, NADH1, NADH3, NADH4, NADH4L and $N A D H 6$ are the mitochondrial genes that are under the strongest purifying selection.

Results of the analysis of the relative synonymous codon usage (RSCU) showed that the codons with adenine and thymine in the third position were overused when compared to other synonymous codons (Table 4), which commonly occurs in other metazoan mitochondrial genomes [36, 37, 42]. This can be observed in the leucine amino acid, i.e., while the TTA codon presented a RSCU value of 3.75 , the codon CTG, which also translates a leucine, showed a RSCU value of 0.14.

\section{RNA genes}

The set of 22 tRNA genes in all species varied in length from $64 \mathrm{bp}$ in trnR gene to $72 \mathrm{bp}$ in $t r n V$ gene (Additional file 1). The AT content ranged from $78.6 \%$ to $79.1 \%$ (Table 3). The anticodons of all tRNAs in Culex species were the same as that of other insects [31-35] (Additional file 1). The conventional cloverleaf-like structure of tRNAs was found in 20 (Additional file 2) of the 22 tRNAs described for Culex species. In contrast, the trnR and trnS1 genes could not be folded into cloverleaf-like structure. In the trnS1, several similar cases were reported in previously sequenced metazoan mitochondrial genomes because of the replacement of the DHU (dihydrouridine) arm by a DHU-loop [43, 44]. The absence of a secondary structure in the trnS1 has been reported for Collembola species [39].

Similar to the mitochondrial genome of other metazoan species [32-37], the $r r n L$ is located between $\operatorname{trnL1}$ and $\operatorname{trn} V$ ribosomal genes, and the $r r n S$ is situated between the $\operatorname{trn} V$ gene and the AT-rich region. In all species, the $r r n L$ and $r r n S$ are 2,124 base pairs long (Additional file 1). The AT content was $82 \%$, a value that is slightly higher than the overall content, however, similar to that observed in the 3rd codon position (Table 3). Both tRNAs and rRNAs genes are more conserved than the PCGs, with only 10 variable sites in tRNAs (throughout $1,462 \mathrm{pb}$ 1,463 bp) and 11 substitutions among 2,124 bp of the two rRNAs genes. Evolutionary studies relative to the tRNA and rRNA in Drosophila and Anopheles showed signatures of negative selection, because non-pairing substitutions such as G-C to G-U can affect the secondary structure of these genes $[41,45]$.

\section{Intergenic spacer sequences}

A total of $52 \mathrm{bp}$ to $56 \mathrm{bp}$ non-coding nucleotides were found in the mitochondrial sequences of the species included in this study (Table 2). The length of each spacer mostly varies from 1 to $5 \mathrm{bp}$, except for two spacers: one located between the trnk and the tranD genes (12 bp in $C x$. coronator, and $11 \mathrm{bp}$ in the remaining species); and the other between trnS2 and NAD1 genes with 19 bp in all samples. Although those spacers account for only $0.3 \%$ of the whole mitochondrial genomes, they are composed almost exclusively of adenine and thymine, with an AT

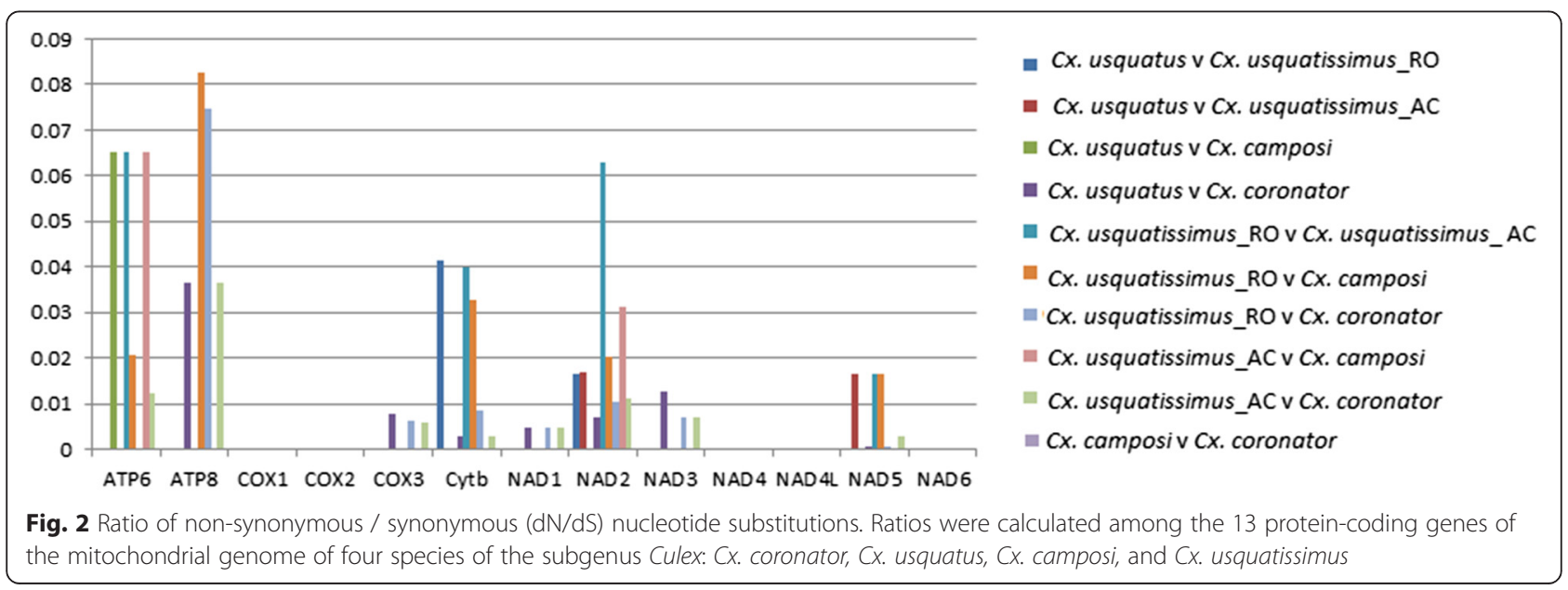


Table 4 Relative synonymous codon usage (RSCU) and overall average of codon usage in the PCGs of Cx. coronator, Cx. usquatus, Cx. camposi, and Cx. usquatissimus

\begin{tabular}{|c|c|c|c|c|c|c|c|c|c|c|c|c|c|c|c|}
\hline $\begin{array}{l}\text { Amino } \\
\text { acid }\end{array}$ & Codon & $\begin{array}{l}\text { Overall } \\
\text { average }\end{array}$ & $\mathrm{RSCU}$ & $\begin{array}{l}\text { Amino } \\
\text { acid }\end{array}$ & Codon & $\begin{array}{l}\text { Overall } \\
\text { average }\end{array}$ & $\mathrm{RSCU}$ & $\begin{array}{l}\text { Amino } \\
\text { acid }\end{array}$ & Codon & $\begin{array}{l}\text { Overall } \\
\text { average }\end{array}$ & $\mathrm{RSCU}$ & $\begin{array}{l}\text { Amino } \\
\text { acid }\end{array}$ & Codon & $\begin{array}{l}\text { Overall } \\
\text { average }\end{array}$ & $\mathrm{RSCU}$ \\
\hline$F$ & $\pi T$ & 218.2 & 1.51 & $S$ & TCT & 59.6 & 1.39 & $Y$ & TAT & 156.4 & 1.5 & C & TGT & 36.0 & 1.2 \\
\hline$F$ & TTC & 71.4 & 0.49 & $S$ & TCC & 38.4 & 0.89 & $Y$ & TAC & 51.4 & 0.5 & C & TGC & 24.6 & 0.8 \\
\hline L & TTA & 297.6 & 3.75 & $S$ & TCA & 86.4 & 2.01 & stop & TAA & - & - & W & TGA & 75.2 & 1.6 \\
\hline L & TTG & 33.4 & 0.42 & P & $\mathrm{CCT}$ & 9.6 & 0.22 & stop & TAG & - & - & W & TGG & 16.4 & 0.4 \\
\hline L & CAA & 50.4 & 0.64 & P & $\mathrm{CCC}$ & 49.6 & 2.00 & $\mathrm{H}$ & CAT & 63.4 & 1.5 & $\mathrm{R}$ & CGT & 2.2 & 0.3 \\
\hline L & CTC & 19.8 & 0.25 & P & CCA & 17.0 & 0.68 & $\mathrm{H}$ & CAC & 21.2 & 0.5 & $\mathrm{R}$ & CGC & 1.0 & 0.1 \\
\hline L & CTA & 63.4 & 0.80 & P & CCA & 31.2 & 1.26 & Q & CAA & 68.0 & 1.7 & $\mathrm{R}$ & CGA & 26.4 & 3.5 \\
\hline L & CTG & 11.0 & 0.14 & P & CCG & 1.6 & 0.06 & Q & CAG & 12.0 & 0.3 & $\mathrm{R}$ & CGG & 1.0 & 0.1 \\
\hline I & ATT & 274.6 & 1.62 & $\mathrm{~T}$ & $\mathrm{ACT}$ & 91.4 & 1.93 & $\mathrm{~N}$ & AAT & 240.4 & 1.5 & $S$ & AGT & 57.0 & 1.3 \\
\hline | & ATC & 63.8 & 0.38 & $\mathrm{~T}$ & $A C C$ & 18.2 & 0.38 & N & AAC & 74.2 & 0.5 & $S$ & AGC & 30.2 & 0.7 \\
\hline M & ATA & 211.6 & 1.68 & $\mathrm{~T}$ & $A C A$ & 74.8 & 1.58 & K & AAA & 204.2 & 1.6 & $S$ & AGA & 38.4 & 0.9 \\
\hline M & ATG & 39.6 & 0.32 & $\mathrm{~T}$ & ACG & 5.0 & 0.11 & K & AAG & 54.2 & 0.4 & $S$ & AGG & 23.8 & 0.6 \\
\hline V & GTT & 48.6 & 1.56 & A & $\mathrm{GCT}$ & 60.2 & 2.68 & D & GAT & 32.0 & 1.6 & G & GGU & 17.2 & 0.7 \\
\hline V & GTC & 2.8 & 0.09 & A & GCC & 6.0 & 0.27 & D & GAC & 8.0 & 0.4 & G & GGC & 0.8 & 0.0 \\
\hline V & GTA & 71.8 & 2.30 & A & GCA & 23.2 & 1.03 & E & GAA & 54.8 & 1.6 & G & GGA & 80.4 & 3.1 \\
\hline V & GTG & 1.8 & 0.06 & $A$ & GCG & 0.4 & 0.02 & $E$ & GAG & 12.0 & 0.4 & G & GGG & 5.6 & 0.2 \\
\hline
\end{tabular}

content that is higher than that observed in the ATcontrol region, reaching $94.5 \%$ in Cx. usquatissimus from Acre (Table 3).

\section{AT-rich control region}

The size variation, ranging from 719 bp in Cx. usquatus to 724 bp in $C x$. coronator (Table 2 ) is within the range variation observed in the mitochondrial genomes reported for other Culicidae (from 531 bp in Anopheles gambiae to $731 \mathrm{bp}$ in Culex quinquefasciatus). Those differences in length were caused by several indels of one to three nucleotides distributed throughout the AT regions of the mitochondrial genomes. Considering both indels and nucleotide substitutions, 34 variable sites were observed in Culex species. Similar to nuclear noncoding DNA, the AT-control region is subjected to a high level of polymorphisms that lead to variation in size and base composition. However, in species of the Anopheles gambiae complex, there is evidence that this region change more slowly than the 3rd codon position of PCGs [46]. Additionally, among different subgenera of Anopheles, there are conservative poly- $\mathrm{T}$ regions of 15 to 18 bp [34]. Comparing the control region of the four Culex species studied, we observed 4 conservative T-stretch regions of 6 to $15 \mathrm{bp}$. This was likely caused because this region contains several regulatory elements, including the origin of replication and transcription of the major strand of the mitochondrial genome [37] and, consequently, has a functional role, which is conserved among genera.

\section{Sliding window analysis}

Mitochondrial DNA is largely employed in phylogeny and evolutionary studies because it has a high mutation rate, maternal inheritance, high number of copies, and intraspecific polymorphisms [47]. Herein, we conducted

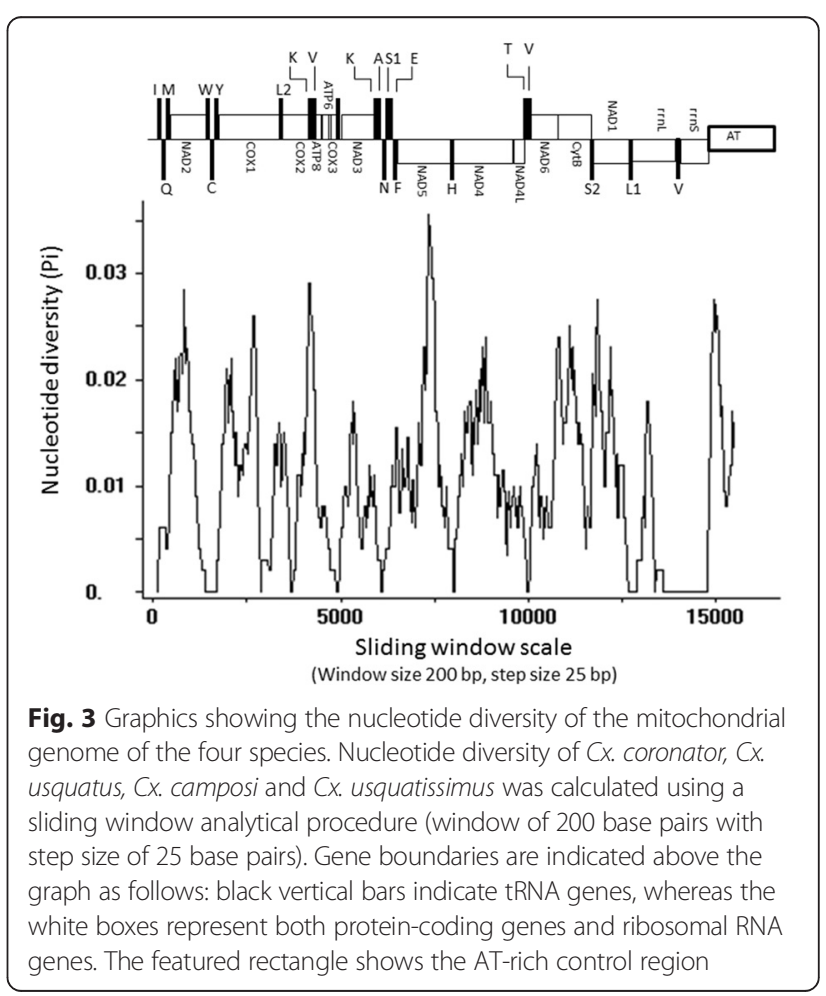


Anopheles darlingi

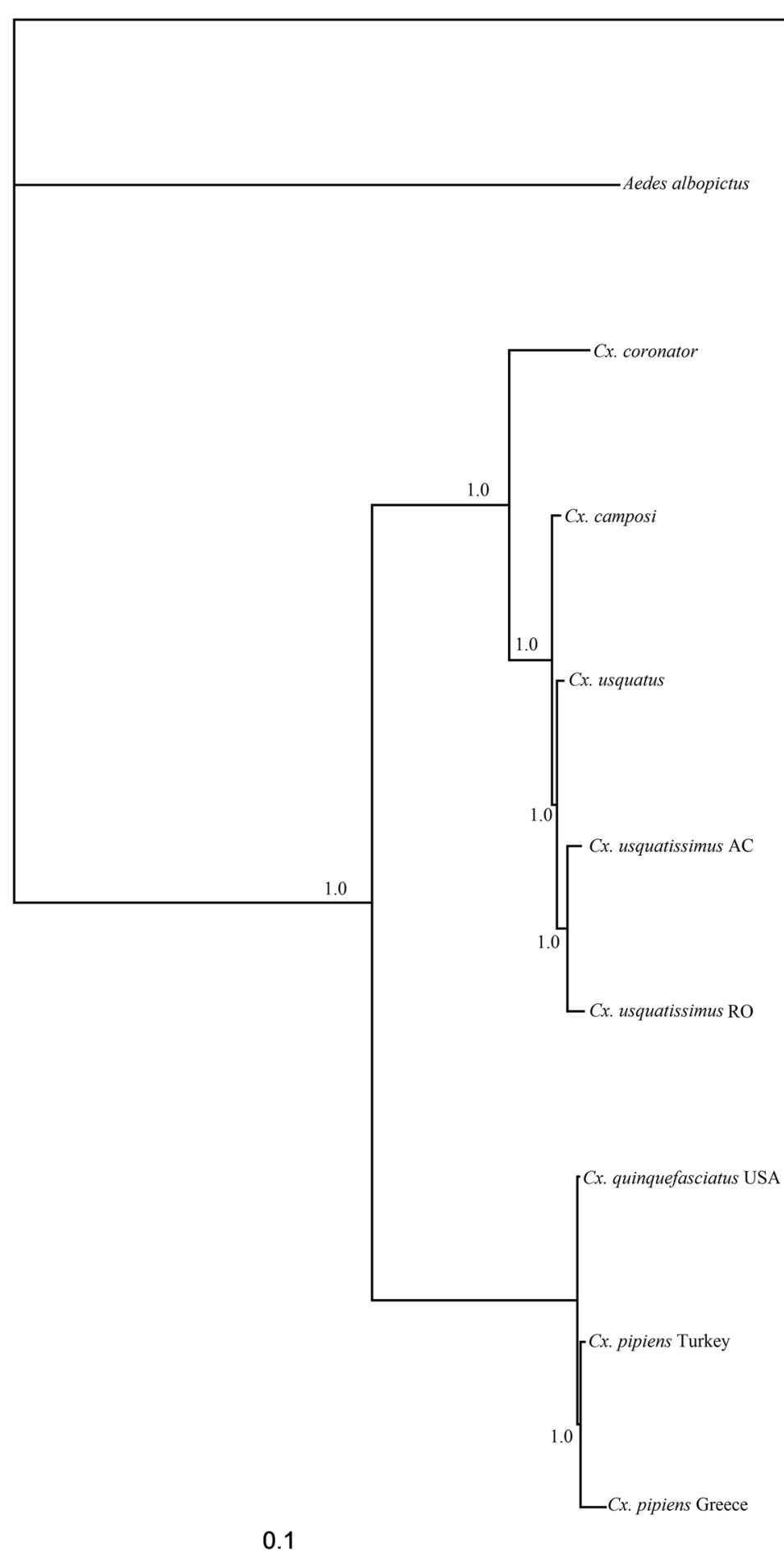

Fig. 4 Bayesian topology generated from the analysis using 13 protein-coding genes of four species of the Coronator Group plus $C$. quinquefasciatus and Cx. pipiens. Numbers placed above the branches indicate the values of Bayesian posterior probabilities. Aedes albopictus and Anopheles darlingi were employed as outgroups. Complete mitochondrial genomes of Cx. quinquefasciatus, two specimens of Cx. pipens, Ae. albopictus and An. darlingi were downloaded from the GenBank 
a sliding window analysis using the alignment of the entire mitochondrial genome of Culex species to verify regions with high nucleotide divergence and thus, identified potential markers that can be employed for future studies focusing on Culex species. Results of the sliding window analysis showed low nucleotide diversity (Pi), ranging from 0.0 to 0.035 (Fig. 3) among species of the Coronator Group. However, nucleotide substitution rates varied across both mitochondrial genomes and within individual genes. Remarkably, the $5^{\prime}$ end of the NADH5 fragment showed the highest nucleotide diversity (0.035) among all mitochondrial genes. The COX1 presented low variation, mainly in its $5^{\prime}$ proximal half. This region is largely employed in studies focusing in Culicidae species, and it is considered as the universal barcode for species identification [48]. Notwithstanding, other descriptive studies focusing on the mitochondrial genome showed that the COX1 is a conserved gene [49-53]. Consequently its utility as a universal barcode needs to be reviewed.

The rrnL and rrnS demonstrated to be the most conserved genes within the mitochondrial genomes of species of the Coronator Group, showing low nucleotide diversity. Although $r r n L$ usually shows high variability among some groups, i.e., Taeniidae [49], Nematoda [50], and Octopodus [54], herein, the highest nucleotide diversity found in the $r r n L$ was 0.02 . Per se, the $r r n L$ and $r r n S$ genes seem not to be good markers for taxonomy and evolutionary studies focusing on species of the Coronator Group.

Considering both the epidemiological importance of $C x$. coronator and the problematic identification of females based on morphological characters, the development of molecular markers can facilitate species identification as well as establish phylogenetic relationships within the group and other closely related species. Taken together, results of the sliding window analysis and the $\mathrm{dN} / \mathrm{dS}$ ratios indicate that the NADH5, ATP8 and ATP6 genes represent potential markers for future investigations regarding species of the Coronator Group, primarily because they retain high variations among PCGs with an elevated proportion of non-synonymous substitutions. Notwithstanding, the low levels of diversity shown herein, demonstrates that the utility of sequences of the mitochondrial gene needs further evaluation in future studies employing a larger sample size and other species of the subgenus Culex as well as other Culex (Culex) species.

\section{Phylogenetic analysis}

Best-fit models selected by the Akaike Information Criterion are showed in Additional file 3. The Bayesian topology generated employing the concatenated PCGs (Fig. 4) yielded two strongly supported (100\% posterior probability) monophyletic clades with the Coronator Group as the sister clade of the lineage composed of species of the $C x$. pipiens complex. Within the clade formed by species of the Coronator Group, the placement of $C x$. coronator as sister of the lineage leading to $C x$. camposi plus $C x$. usquatus plus $C x$. usquatissimus was strongly supported (100 \% Bayesian posterior probability). Additionally, divergence among species from this group under Maximum Composite Likelihood (MCL) was low (Table 5), ranging from $0.2 \%$ between $C x$. usquatus and $C x$. camposi to $1.4 \%$ between $C x$. coronator and $C x$. usquatissimus (from Acre and Rondônia). The low nucleotide divergence observed among the mitochondrial genes of species of the Coronator Group supports the close phylogenetic relationships observed in previous studies [3-5]. As hypothesized by Lloyd et al. 2012 [55], the high statistical support for the clades suggests that many other species can be included in the PCGs analyses of species of the subgenus Culex. However, if more species were included in the study, likely the phylogenetic signal of the mitochondrial genes would be changed. For instance, studies based on morphological phylogeny [56] and COX1 barcode sequence data of several species of the genus Culex [4] were not capable of supporting phylogenetic relationships among species of the Coronator Group and other closely related species such as $C x$. surinamensis and $C x$. maxi. Those results suggest that $C x$. surinamensis

Table 5 Average of nucleotide divergence under Maximum Composite Likelihood of 13 protein-coding genes of the mitochondrial genome of $C$. coronator, Cx. usquatus, Cx. camposi, and Cx. usquatissimus and four specimens obtained from GenBank. The averages are expressed as percentages; GenBank accession numbers are indicated between brackets

\begin{tabular}{lllllll}
\hline & 1 & 2 & 3 & 4 & 5 & 6 \\
\hline 1. CX. pipiens Greece [HQ724615] & & & & & & \\
2. CX. pipiens Turkey [HQ724616] & 0.3 & & & & & \\
3. CX. quinquefasciatus USA [HQ724617] & 0.1 & 0.3 & & & & \\
4. CX. usquatissimus AC & 3.9 & 4.1 & 3.8 & & & \\
5. CX. usquatissimus RO & 4.0 & 4.1 & 3.9 & 0.3 & & \\
6. CX. usquatus & 3.9 & 4.0 & 3.8 & 0.3 & 0.3 & 1.3 \\
7. CX. camposi & 3.8 & 3.9 & 3.7 & 0.3 & 0.4 & 1.3 \\
8. CX. coronator & 4.0 & 4.2 & 3.9 & 1.4 & 1.4 & \\
\hline
\end{tabular}


An. darlingi

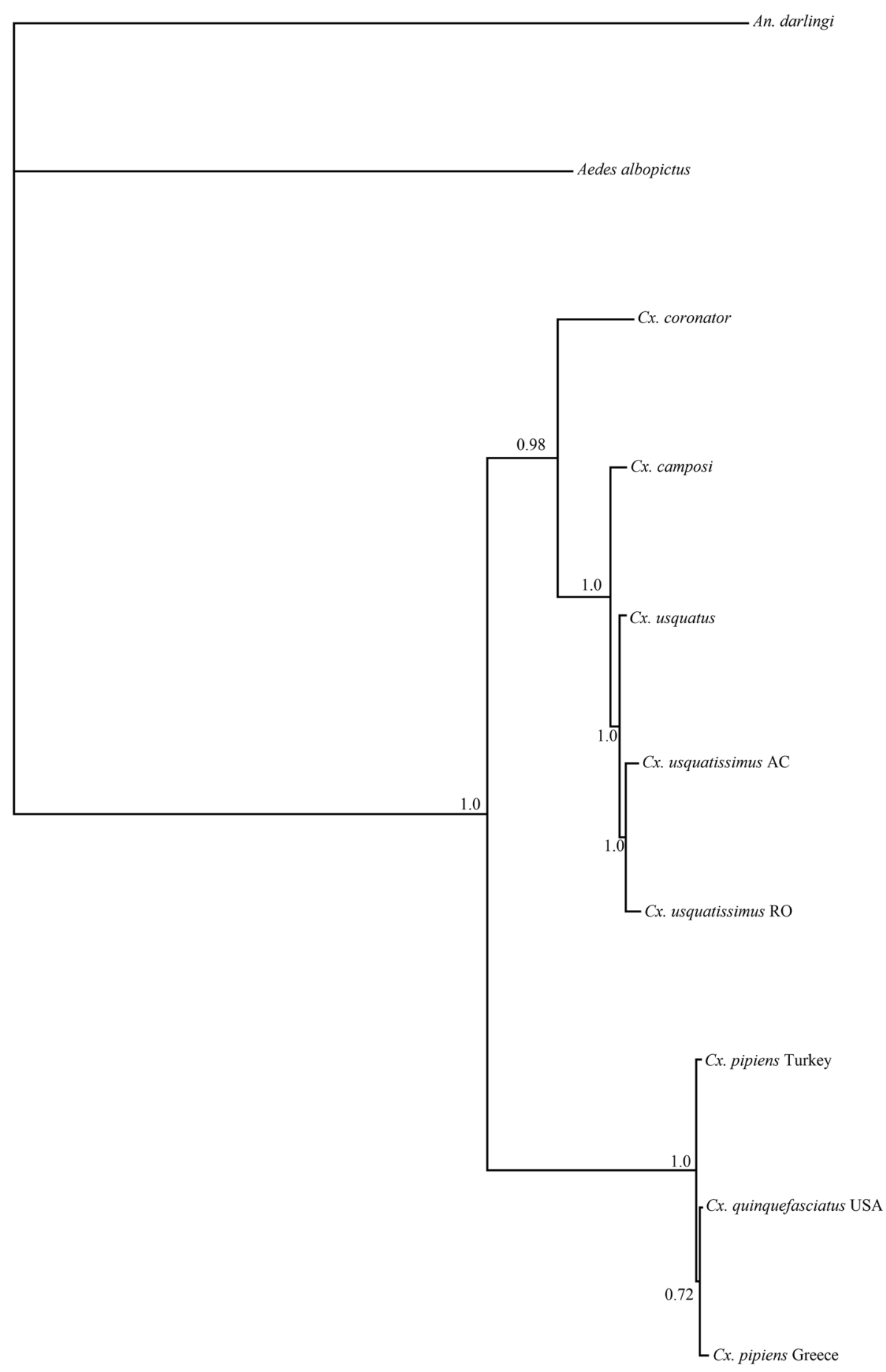

0.1

Fig. 5 Bayesian topology generated from the analysis using ATP6, ATP8 and NADH5 protein-coding genes of four species of the Coronator Group plus two species of Cx. pipiens complex. Numbers placed at the branches indicate Bayesian posterior probabilities. Aedes albopictus and Anopheles darlingi were employed as outgroups. Mitochondrial genomes of $C$. quinquefasciatus, two specimens of Cx. pipens, Ae. albopictus and An. darlingi were downloaded from the GenBank 
and Cx. maxi may share their ancestor with current species included in Coronator Group and as such, they should be included in the group. However, further studies need to be developed to address this hypothesis.

In order to address the effectiveness of the ATP6, ATP8 and $N A D H 5$ for reconstructing phylogenetic relationships within the Coronator Group, a Bayesian analysis was performed only with these genes (Fig. 5). Within the Coronator Group, the topology yielded was the same of that performed with all genes, demonstrating the potential of those genes for further evolutionary studies with this group. Interestingly, for $C x$. pipiens complex species, results of Bayesian analysis recovered a polytomy between $C x$. quinquefasciatus and $C x$. pipiens. Those results are important to show how evolutionary behavior of the genes are different among groups of species, even within the same subgenus, and how carefully researchers need to be when selecting a molecular marker.

\section{Conclusions}

The complete mitochondrial genomes of $C x$. usquatus, $C x$. usquatissimus, $C x$. coronator, and $C x$. camposi share the same gene order and gene content of other Culicidae species with the mitochondrial genome reported to date. The overall length and the AT content of the four Culex species are within the range observed in species of the Anopheles albitarsis complex, Cx. quinquefasciatus, and Ae. aegypti. Except for $\operatorname{trnR}$ and $\operatorname{trnS1}$, the tRNAs were folded into the typical cloverleaf-like structure. Similar to other metazoan and species of the family Culicidae, the control region presented some conservative poly $\mathrm{T}$ - stretches, which seems to be involved in the functional roles of mitochondrial genome. Results of the Bayesian phylogeny corroborated the monophyly of the Coronator Group. Nevertheless, new insights on the evolution of the group can be addressed using a larger species sampling, including morphologically similar species and species of other Culex subgenera, for example, Lutzia, Phenacomyia and Phytothelmatomyia species. Probably because of the functional roles played in the respiratory chain by the mitochondrial genome, PCGs showed high purifying selection and low nucleotide divergence among the species investigated here.

\section{Additional files}

Additional file 1: Mitochondrial genomes organization of species studied. Format: Xls. (XLSX 28 kb)

Additional file 2: Predicted secondary structures for 20 tRNA genes of Coronator Group. Colored dots indicate Watson-Crick base pairing; red dots indicate G-C base pairing. Format: png. (PNG 671 kb)

Additional file 3: Best-fit model chosen for each gene under Akaike information criterion (AIC). (XLSX $9 \mathrm{~kb}$ )

\section{Competing interests}

The authors declared that they have no competing interests.

\section{Authors' contributions}

BDS, PGF and MAMS conceived the idea. TMPO, SSS and RP were responsible for mitochondrial genome amplification and library preparation for Illumina Sequencing. PGF analyzed the Illumina data, did the assembly and annotated the genes in the genome. BDS, MAMS wrote the manuscript with the help of PGS, SSS, ESB and TMPO. All authors read and approved the final version of the manuscript.

\section{Authors' information}

Not applicable.

\section{Availability of data and materials}

Not applicable.

\section{Acknowledgments}

This work was supported by FAPESP (Grant 2014/26229-7) and Conselho Nacional de Desenvolvimento Científico e Tecnológico (CNPq) (Grant 301666/2011-3).

\section{Author details}

${ }^{1}$ Departamento de Epidemiologia, Faculdade de Saúde Pública, Universidade de São Paulo, São Paulo, Brazil. ²Department of Life Sciences, Natural History Museum, Cromwell Road, London, England. ${ }^{3}$ Superintendência de Controle de Endemias, Secretaria de Estado da Saúde de São Paulo, Araraquara, São Paulo, Brazil. ${ }^{4}$ Department of Pathology, LIM 03, Hospital das Clínicas (HC), School of Medicine, University of São Paulo, São Paulo, Brazil.

Received: 21 April 2015 Accepted: 23 September 2015 Published online: 21 October 2015

\section{References}

1. Forattini OP. Entomologia Médica. $2^{\circ}$ Volume. Culicini: Culex, Aedes e Psorophora. São Paulo, Editora da Universidade de São Paulo; 1965. Pages: 121-129.

2. Bram R. Classification of Culex subgenus Culex (Diptera: Culicidae). Proc US Nat Mus. 1967;120:1-123.

3. Demari-Silva B, Vesqueiro FT, Sallum MAM, Marrelli MT. Taxonomic and phylogenetic relationships between species of the genus Culex (Diptera: Culicidae) from Brazil inferred from the cytochrome c oxidase I mitochondrial gene. J Med Entomol. 2011;48:272-9.

4. Laurito M, de Oliveira TMP, Almirón WR, Sallum MAM. COI barcode versus morphological identification of Culex (Culex) (Diptera: Culicidae) species: a case study using samples from Argentina and Brazil. Mem Inst Oswaldo Cruz. 2013;108:110-22.

5. Vesgueiro FT, Demari-Silva B, Malfronte RS, Sallum MAM, Marrelli MT. Intragenomic variation in the second internal transcribed spacer of the ribosomal DNA of species of the genera Culex and Lutzia (Diptera: Culicidae). Mem Inst Oswaldo Cruz. 2011;106:1-8.

6. Consoli RAGB, Lourenço-de-Oliveira R. Principais mosquitos de importância sanitária no Brasil. Rio de Janeiro: FIOCRUZ; 1998

7. Forattini OP. Culicidologia Médica: identificação, biologia e epidemiologia. São Paulo: EDUSP; 2002. pp. 702-703.

8. Alto BW, Connelly CR, O'Meara GF, Hickman D, Karr N. Reproductive biology and susceptibility of Florida Culex coronator to infection with West Nile Virus. Vector Borne Zoonotic Dis. 2014;14:606-14

9. Saraste M. Oxidativephosphorylationat thefindesiècle. Science. 1999:283:1488-93.

10. Boore JL. Animal mitochondrial genomes. Nucleic Acids Res. 1999;27:1767-80.

11. Goddard JM, Wolstenholme DR. Origin and direction of replication in mitochondrial DNA molecules from Drosophila melanogaster. Proc Natl Acad Sci U S A. 1978:75:3886-90

12. Botero-Castro F, Tilak MK, Justy F, Catzeflis F, Delsuc F, Douzery EJ. Nextgeneration sequencing and phylogenetic signal of complete mitochondrial genomes for resolving the evolutionary history of leaf-nosed bats (Phyllostomidae). Mol Phylogenet Evol. 2013;693:728-39.

13. Schierwater B, Stadler P, Desalle R, Podsiadlowski L. Mitogenomic and metazoan evolution. Mol Phylogenet Evol. 2013;69:311-2.

14. Williams ST, Foster PG, Littlewood DT. The complete mitochondrial genome of a turbinid vetigastropod from MiSeq Illumina sequencing of genomic DNA and steps towards a resolved gastropod phylogeny. Gene. 2014;533:38-47. 
15. Foster PG, Bergo ES, Bourke BP, Oliveira TM, Nagaki SS, Sant'Ana DC, et al. Phylogenetic analysis and DNA-based species confirmation in Anopheles (Nyssorhynchus). PLoS One. 2013;8:e54063.

16. Folmer $\mathrm{O}$, Black $\mathrm{M}$, Hoeh $\mathrm{W}$, Lutz R, Vrijenhoek R. DNA primers for amplification of mitochondrial cytochrome c oxidase subunit I from diverse metazoan invertebrates. Mol Mar Biol Biotechnol. 1994;3:294-9.

17. Kambhampati S, Smith PT. PCR primers for amplification of four insect mitochondrial gene fragments. Insect Mol Biol. 1995:4:233-6.

18. Chevreux B, Wetter $T$, Suhai $S$. Genome sequence assembly using trace signals and additional sequence information. Comput Sci Biol Proc. 1999:99:45-56. German Conference on Bioinformatics GCB.

19. Milne I, Stephen G, Bayer M, Cock PJ, Pritchard L, Cardle L, et al. Using Tablet for visual exploration of second-generation sequencing data. Brief Bioinform. 2013;14:193-202

20. Bernt $M$, Donath $A$, Jühling $F$, Externbrink F, Florentz C, Fritzsch $G$, et al MITOS: Improved de novo Metazoan mitochondrial genome annotation. Mol Phylogenet Evol. 2013;69:313-9.

21. Birney E, Durbin R. Using Gene Wise in the Drosophila annotation experiment. Genome Res. 2000;10:547-8.

22. Tamura K, Stecher G, Peterson D, Filipski A, Kumar S. MEGA6: Molecular Evolutionary Genetics Analysis Version 6.0. Mol Phylogenet Evol. 2013;30:2725-9.

23. Perna NT, Kocher TD. Patterns of nucleotide composition at fourfold degenerate sites of animal mitochondrial genomes. J Mol Evol. 1995;41:353-8.

24. Schattner P, Brooks AN, Lowe TM. The tRNAscan-SE, snoscan and snoGPS web servers for the detection of tRNAs and snoRNAs. Nucleic Acids Res. 2005;1:33.

25. Librado P, Rozas J. DnaSPv5: a software for comprehensive analysis of DNA Bioinformatics. 2009;25:1451-2.

26. Zhang Z, Li J, Zhao XQ, Wang J, Wong GK, Yu J. KaKs Calculator: Calculating $\mathrm{Ka}$ and $\mathrm{Ks}$ through model selection and model averaging. Genomics Proteomics Bioinformatics. 2006;4:259-63.

27. Larkin MA, Blackshields G, Brown NP, Chenna R, McGettigan PA, McWilliam $\mathrm{H}$, et al. ClustalW and ClustalX version2.0. Bioinformatics. 2007;23:2947-8.

28. BioEdit HT. a user-friendly biological sequence alignment editor and analysis program for windows 95/98/NT. Nucleic Acids Symp Ser (Oxf). 1999:41:95-8.

29. Posada D. jModelTest:phylogenetic model averaging. Mol Biol Evol. 2008:25:1253-6.

30. Huelsenbeck JP, Ronquist F. MRBAYES: Bayesian inference of phylogenetic trees. Bioinformatics. 2001;17:754-5.

31. Beard CB, Hamm DM, Collins FH. The mitochondrial genome of the mosquito Anopheles gambiae: DNA sequence, genome organization, and comparisons with mitochondrial sequences of other insects. Insect Mol Biol. 1993;2:103-24

32. Behura SK, Lobo NF. Haas B, deBruyn B, Lovin DD, Shumway MF et al. Complete sequences of mitochondrial genomes of Aedes aegypti and Culex quinquefasciatus and comparative analysis of mitochondrial DNA fragments inserted in the nuclear genomes. Insect Biochem Mol Biol. 2011;41:770-7.

33. Logue K, Chan ER, Phipps T, Small ST, Reimer L, Henry-Halldin C, et al. Mitochondrial genome sequences reveal deep divergences among Anopheles punctulatus sibling species in Papua New Guinea. Malar J. 2013;12:64.

34. Krzywinski J, Li C, Morris M, Conn JE, Lima JB, Povoa MM, et al. Analysis of the evolutionary forces shaping mitochondrial genomes of a Neotropical malaria vector complex. Mol Phylogenet Evol. 2011;58:469-77.

35. Lloyd R, Streeter SD, Foster PG, Littlewood DTJ, Huntley J, Beckham GT, et al. The complete mitochondrial genome of Limnoria quadripunctata Holthuis (Isopoda: Limnoriidae). Mitochondrial DNA. 2014;10:1-2.

36. Chen YH, Huang DY, Wang Y, Zhu CD, Hao JS. The complete mitochondrial genome of the endangered Apollo butterfly, Parnassius apollo (Lepidoptera: Papilionidae) and its comparison to other Papilionidae species. J Asia-Pacific Entomology. 2014;17:663-71.

37. Sun WY, Xu DL, Chen HX, Shi W, Sundberg P, Sun SC. Complete mitochondrial genome sequences of two parasitic/commensal nemerteans, Gononemertes parasite and Nemertopsis tetraclitophila (Nemertea: Hoplonemertea). Parasit Vectors. 2014;19:273.

38. Sun Z, Wan DG, Murphy RW, Ma L, Zhang XS, Huang DW. Comparison of base composition and codon usage in Insects. Genes Genomics. 2009;31:65-71

39. Nardi F, Carapelli A, Fanciulli PP, Dallai R, Frati F. The complete mitochondrial DNA sequence of the basal hexapod Tetrodontophora bielanensis: evidence for heteroplasmy and tRNA translocations. Mol Biol Evol. 2001:18:1293-304

40. de Bruijn MH. Drosophila melanogaster mitochondrial DNA, a novel organization and genetic code. Nature. 1983;304:234-41.

41. Krzywinski J, Grushko OG, Besansky NJ. Analysis of the complete mitochondrial DNA from Anopheles funestus: an improved dipteran mitochondrial genome annotation and a temporal dimension of mosquito evolution. Mol Phylogenet Evol. 2006;39:417-23.

42. Salvato $P$, Simonato M, Battisti A, Negrisolo E. The complete mitochondrial genome of the bag-shelter moth Ochrogaster lunifer (Lepidoptera, Notodontidae). BMC Genomics. 2008:9:331.

43. Montooth KL, Abt DN, Hofmann JW, Rand DM. Comparative genomics of Drosophila mtDNA: novel features of conservation and change across functional domains and lineages. J Mol Evol. 2009;69:94-114.

44. Zhao F, Huang DY, Sun XY, Shi QH, Hao JS, Yang Q. The first mitochondrial genome for the butterfly family Riodinidae (Abisara fylloides) and its systematic implications. Zoological Res. 2013;34:109-19.

45. Cook CE. The complete mitochondrial genome of the stomatopod crustacean Squilla mantis. BMC Genomics. 2005:6:105.

46. Caccone A, Garcia BA, Powell JR. Evolution of the mitochondrial DNA control region in the Anopheles gambiae complex. Insect Mol Biol. 1996:5:51-9.

47. Moritz C, Dowling TE, Brown WM. Evolution of Animal Mitochondrial DNA: Relevance for Population Biology and Systematics. Annu Rev Ecol Syst. 1987;18:269-92.

48. Hebert PD, Cywinska A, Ball SL, de Waard JR. Biological identifications through DNA barcodes. Proc Biol Sci. 2003;270:313-21.

49. Jia WZ, Yan HB, Guo AJ, Zhu XQ, Wang YC, Shi WG, et al. Complete mitochondrial genomes of Taenia multiceps, T.hydatigena and T.pisiformis: additional molecular markers for tape worm genus of human and animal health significance. BMC Genomics. 2010;11:447.

50. Xie Y, Zhang Z, Niu L, Wang Q, Wang C, Lan J, et al. The mitochondria genome of Baylisascaris procyonis. PLoS One. 2011;6:e27066.

51. Jabbar A, Beveridge I, Mohandas N, Chilton NB, Littlewood DT, Jex AR, et al. Analyses of mitochondrial amino acid sequence datasets support the proposal that specimens of Hypodontus macropi from three species of macropodid hosts represent distinct species. BMC Evol Biol. 2013:13:259.

52. Broughton RE, Milam JE, Roe BA. The complete sequence of the zebra fish (Daniorerio) mitochondrial genome and evolutionary patterns invertebrate mitochondrial DNA. Genome Res. 2001;11:1958-67.

53. Le TH, Pearson MS, Blair D, Dai N, Zhang LH, McManus DP. Complete mitochondrial genomes confirm the distinctiveness of the horse-dog and sheep-dog strains of Echinococcus granulosus. Parasitology. 2002;124:97-112.

54. Cheng R, Zheng X, Ma Y, Li Q. The complete mitochondrial genomes of two octopods Cistopus chinensis and Cistopus taiwanicus: Revealing the phylogenetic position of the genus Cistopus within the Order Octopoda. PLoS One. 2013;17:e842.

55. Lloyd RE, Foster PG, Guille M, Littlewood DT. Next generation sequencing and comparative analyses of Xenopus mitogenomes. BMC Genomics. 2012;13:496

56. Laurito M, Almirón W. Phylogenetic relationships of Culex (Culex) species (Diptera, Culicidae) from Argentina based on morphological characters. Zootaxa. 2013:3652:117-55. 